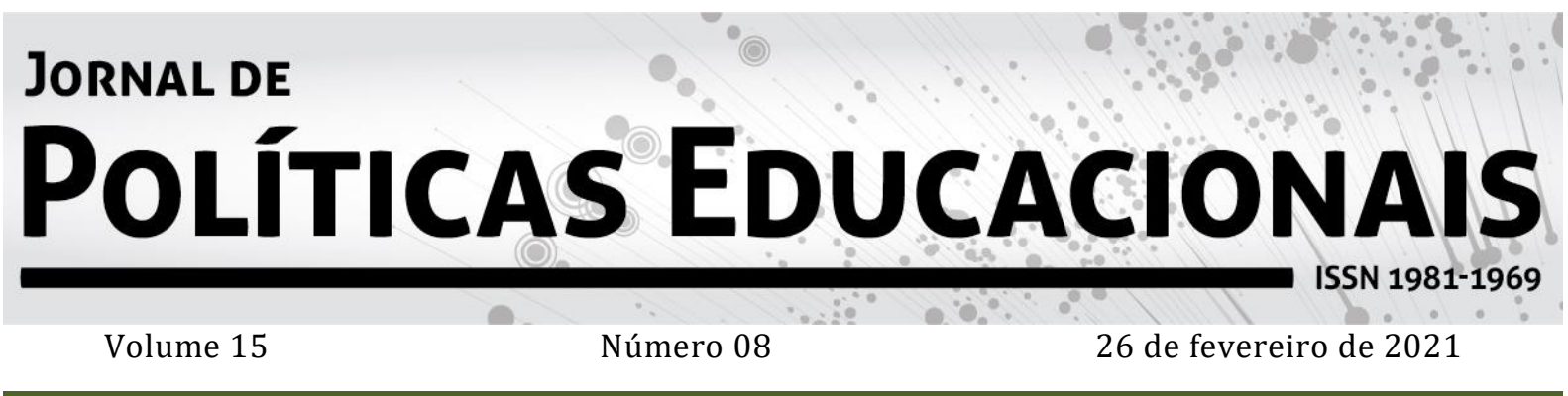

\title{
Internacionalização das políticas educacionais brasileiras: desdobramentos sobre a missão do ensino escolar
}

\author{
Internationalization of Brazilian educational policies: developments on \\ the mission of school education
}

\section{Internacionalización de las políticas educativas brasileñas: avances en la misión de la educación escolar}

Cleonara Maria Schwartz Patrícia Veronesi Batista2

Citação: SCHWARTZ, C. M., BATISTA, P. V. Internacionalização das políticas educacionais brasileiras: desdobramentos sobre a missão do ensino escolar. Jornal de Políticas Educacionais. V. 15, n. 08. Fevereiro de 2021.

http://10.5380/jpe.v15i0.77872

\begin{abstract}
Resumo
Apresenta uma análise das influências de diretrizes internacionais na história das reformas educacionais brasileiras, sobretudo a partir de 1990, momento considerado divisor de águas na inserção de forças neoliberais sobre diversos cenários brasileiros. 0 aporte teórico-metodológico parte da perspectiva bakhtiniana de signo ideológico como caminho para evidenciar realidades sobre as quais as reformas educacionais investigadas se fundamentam. Realiza assim, uma pesquisa bibliográfica, de caráter exploratório e analítico, que buscou dialogar com artigos e dissertações para analisar como diretrizes provenientes de conferências e/ou fóruns mundiais de educação vêm, historicamente, repercutindo na elaboração de planos e/ou de leis responsáveis por importantes reformas educacionais no Brasil, com propósito de destacar principais marcos da internacionalização; identificar instituições internacionais que se destacam, suas motivações e interesses; e compreender como a internacionalização da educação reverbera na qualidade e na missão do ensino escolar brasileiro. Observa-se, por fim, um esvaziamento do potencial transformativo das políticas públicas, da essência pedagógica da escola, para atuar em causas de
\end{abstract}

\footnotetext{
1 Doutora em Educação pela USP. Professora Adjunta da Ufes / Centro de Educação / Programa de PósGraduação em Educação (Ufes). Coordenadora do Grupo de Pesquisa Alfabetização, Leitura e Escrita, vinculado ao CNPq. Vice-coordenadora do Núcleo de Estudos e Pesquisas em Alfabetização, Leitura e Escrita do Espírito Santo (Nepales). Vitória, ES. Brasil. Orcid: https://orcid.org/0000-0003-4411-2234. Email: cleonara.schwartz@ufes.br 2Mestranda em Educação pela UFES. Vitória, ES. Brasil. Orcid: https://orcid.org/0000-0002-3774-4519. E-mail: veronesi.pb@gmail.com
} 
alívio social, comprometendo avanços sobre os índices de reprovação, sobre o baixo desempenho dos alunos, refletindo, por vezes, no fracasso escolar e na exclusão social.

Palavras-chave:Políticas Públicas, Diretrizes Internacionais, História das Reformas Educacionais do Brasil.

\begin{abstract}
It presentsananalysis of the influences of international guidelines in the history of Brazilian educational reforms, especially since 1990, considered a watershed in the insertion of neoliberal forces on different Brazilian scenarios. The theoretical-methodological contribution starts from the Bakhtinian perspective of ideological sign as a way to highlight the realities on which the educational reforms investigated are based. Anexploratoryandanalyticalbibliographicalresearchwas carried out, which sought to dialogue with articles and dissertations to analyze how directives from conferences and / or world forums of education have historically had repercussions in the elaboration of plans and / or laws responsible for important educational reforms in Brazil, with the purpose of highlighting the main internationalization milestones; identify outstanding international institutions, their motivations and interests; and to understand how the internationalization of education reverberates in the quality and mission of Brazilian school education. Finally, there is an emptying of the transformative potential of public policies, of the school's pedagogical essence, to act on causes of social relief, compromising advances on failure rates, on the low performance of students, sometimes reflecting school failure and social exclusion.
\end{abstract}

Keywords: Public Policies, International Guidelines, History of Educational Reforms in Brazil.

\title{
Resumen
}

Presenta unanálisis de las influencias de los lineamientos internacionales en la historia de las reformas educativas brasileñas, especialmente desde 1990, momento considerado un hito en la inserción de las fuerzas neoliberales en varios escenarios brasileños.El aporte teórico-metodológico parte de la perspectiva bakhtiniana signo ideológico como una forma de resaltar las realidades en las que se basan las reformas educativas investigadas.Así, realiza una investigación bibliográfica exploratoria y analítica, que buscó dialogar con artículos y disertaciones para analizar cómo los lineamientos de las conferencias y / o foros mundiales de educación han repercutido históricamente en la elaboración de planes y / o leyes responsables de importantes reformas educativas en Brasil, con el propósito de resaltar los principales hitos de la internacionalización; identificar instituciones internacionales destacadas, sus motivaciones e intereses; y comprender cómo la internacionalización de la educación repercute en la calidad y misión de la educación escolar brasileña.Finalmente, se produce un vaciamiento del potencial transformador de las políticas públicas, de la esencia pedagógica de la escuela, para actuar sobre causas de alivio social, comprometiendo avances en tasas de reprobación, en el bajo desempeño de los estudiantes, reflejando en ocasiones fracaso escolar y exclusión social.

Palabras clave: Políticas publicas, Directrices internacionales, Historia de las reformas educativas en Brasil.

\section{Introdução}

Entendemos que as políticas públicas compreendem instrumentos de fundamental importância para qualquer administração pública (seja municipal, seja estadual, seja federal), tendo em vista seu potencial de incidir sobre demandas que surgem da sociedade civil, podendo ser pensadas, atualizadas e substituídas, conforme a dinâmica e as prioridades de cada realidade. Entretanto, ressaltamos que esse caráter estratégico das políticas públicas se deve ao fato de emergirem e se desenvolverem localmente, mediante o envolvimento e a participação daqueles que vivem e conhecem as realidades. 
Ao avaliar as políticas que marcam a história da educação no Brasil, percebe-se forte influência de diretrizes internacionais, desde a década de 1990, quando projetos neoliberais ganham força no cenário político-econômico-social brasileiro, o que, por sua vez, tende a colocar em risco o potencial transformador da política pública, não mais pensada localmente e colocada à disposição de interesses macropolíticos. Desta forma, buscamos problematizar neste estudo: como diretrizes internacionais têm influenciado na elaboração de importantes reformas educacionais no Brasil? E principalmente, quais as consequências dessas influências para a qualidade e para a missão do ensino escolar brasileiro?

Vale ressaltar que são inúmeras as pesquisas que investigam repercussões de diretrizes internacionais nas políticas públicas de educação no Brasil ${ }^{3}$, trata-se de uma área de estudos com grande volume de produção no cenário acadêmico brasileiro. Nesse sentido, buscamos contribuir com o campo teórico-metodológico de investigação ao optarmos pela perspectiva bakhniana de linguagem, a qual tem sido privilegiada em nossos estudos e que se mostra ainda pouco explorada nas análises de políticas públicas ${ }^{4}$. Sendo assim, partimos da concepção de signo ideológico (a qual estabelece relação com outros conceitos, como: linguagem, enunciado, palavra e diálogo) de Bakhtin (2006), pois nos permite estabelecer diálogo com pesquisas dedicadas ao histórico de reformas educacionais brasileiras, concebendo-as como enunciados, dotados de palavras, de signos sociais que apontam para realidades ideológicas, as quais precisam ser compreendidas para avaliarmos as influências das diretrizes internacionais sobre o cenário educacional brasileiro.

Realizou-se assim uma pesquisa bibliográfica, de caráter exploratório e analítico, mediante fontes encontradas na Biblioteca Digital Brasileira de Teses e Dissertações (BDTD) do Instituto Brasileiro de Informação em Ciência e Tecnologia (Ibict) e no Portal de Periódicos da Coordenação de Aperfeiçoamento de Pessoal de Nível Superior (Capes) ${ }^{5}$. Além das referidas fontes, foi necessário buscar por pesquisas

\footnotetext{
${ }^{3}$ Algumas serão mencionadas nos próximos capítulos.

${ }^{4}$ Nenhum dos estudos com os quais tivemos contato na ocasião desta pesquisa fundamentou-se na perspectiva bakhtiniana de linguagem.

${ }^{5}$ Após a seleção dos termos (políticas educacionais/reformas educacionais/políticas públicas educacionais e organismos internacionais/diretrizes internacionais), formulou-se as estratégias de busca relacionando as expressões mediante o uso do operador booleano AND, buscando por estudos que relacionassem os conceitos, assim como seus correlatos. Aplicou-se o recorte temporal para seleção de materiais referentes aos últimos seis anos (2013-2018 ou 2014-2019, conforme possibilidade de cada base) e
} 
SCHWARTZ, C. M., BATISTA, P. V. Internacionalização das políticas educacionais brasileiras: desdobramentos sobre a missão do ensino escolar

complementares que apresentassem históricos das reformas educacionais brasileiras, as quais foram encontradas no Google Acadêmico e utilizadas como bibliografias complementares para pensar o problema de pesquisa. No entanto, nem todas as fontes selecionadas foram utilizadas na edição deste texto.

Diante do exposto, temos o objetivo geral de analisar como diretrizes provenientes de conferências e/ou de fóruns mundiais de educação vêm, historicamente, repercutindo na elaboração de importantes reformas educacionais e na missão do ensino escolar brasileiro. E para alcançar tal objetivo, algumas ações específicas foram planejadas:

- destacar principais marcos a partir dos quais se fazem presentes influências de diretrizes internacionais nas políticas públicas educacionais do Brasil;

- identificar instituições internacionais que se destacam no processo de internacionalização da educação, avaliar motivações e interesses;

- compreender como a internacionalização da educação reverbera na missão do ensino escolar brasileiro.

\section{Referencial teórico-metodológico}

Inúmeros são os estudiosos que abordam as repercussões de diretrizes internacionais nas políticas públicas de educação no Brasil ${ }^{6}$, todos partem da perspectiva de que a área educacional é um campo marcado por disputas, no qual se faz ausente qualquer perspectiva de neutralidade, sendo, sobretudo, uma área propagadora de concepções e de práticas sociais fincadas na lógica neoliberal, apontando para determinadas realidades ideológicas.

Bakhtin (2006) nos diz que a realidade ideológica “[...] é a realidade objetiva dos signos sociais. As leis dessa realidade são [...] diretamente determinadas pelo conjunto das leis sociais e econômicas [...]" (BAKHTIN, 2006, p. 34) e é na linguagem, por meio da palavra, que se pode identificar as formas ideológicas da comunicação semiótica:

\footnotetext{
optou-se por estudos revisados por pares no Portal de Periódicos da Capes. Após a análise dos resumos, seis documentos foram selecionados para leitura, sistematização e discussão.
}

${ }^{6}$ Dentre eles estão: Frigotto e Ciavatta (2003), Evangelista e Shiroma (2006), entre outros. 
[...] As palavras são tecidas a partir de uma multidão de fios ideológicos e servem de trama a todas as relações sociais em todos os domínios. É portanto claro que a palavra será sempre o indicador mais sensível de todas as transformações sociais, mesmo daquelas que apenas despontam, que ainda não tomaram forma, que ainda não abriram caminho para sistemas ideológicos estruturados e bem formados. A palavra constitui o meio no qual se produzem lentas acumulações quantitativas de mudanças que ainda não tiveram tempo de adquirir uma nova qualidade ideológica, que ainda não tiveram tempo de engendrar uma forma ideológica nova e acabada. A palavra é capaz de registrar as fases transitórias mais íntimas, mais efêmeras das mudanças sociais (BAKHTIN, 2006, p. 40, itálico do autor).

A palavra mostra-se, portanto, “[...] o fenômeno ideológico por excelência [...]” (BAKHTIN, 2006, p. 34, itálico do autor), capaz de embasar nosso problema de pesquisa, nos levando a enunciados que apontem para repercussões da internacionalização das políticas educacionais brasileiras no decorrer das últimas décadas.

Concordamos com Bakthin (2006) quando afirma que alterações na organização social ou nas condições de interação, resultam em modificações do signo linguístico, estreitamente relacionado a expectativas e a ambições sociais, originárias de grupos e de épocas específicas, mediante forças ideológicas. 0 mesmo pode ser percebido em consequência dos acordos globais firmados entre nações de todo o mundo, mediante as influências de novas diretrizes e perante a atuação de organismos internacionais, que acabam por resultar, consequentemente, na implementação de reformas, leis e programas educacionais, afinal, como nos diz o filósofo da linguagem:

Todo signo [...] resulta de um consenso entre indivíduos socialmente organizados no decorrer de um processo de interação. Razão pela qual as formas do signo são condicionadas tanto pela organização social de tais indivíduos como pelas condições em que a interação acontece. Uma modificação destas formas ocasiona uma modificação do signo [...] (BAKHTIN, 2006, p. 43, itálico do autor).

Não devemos perder de vista, aliás, que o ser tanto influencia, quanto é influenciado por tais transformações, e o que determina essa relação é o "[...] confronto de interesses sociais nos limites de uma só e mesma comunidade semiótica, ou seja: $a$ luta de classes" (BAKHTIN, 2006, p. 45, itálico do autor).

[...] Sabemos que cada palavra se apresenta como uma arena em miniatura onde se entrecruzam e lutam os valores sociais de orientação contraditória. A palavra revela-se, no momento de sua expressão, como o produto da interação viva das forças sociais (BAKHTIN, 2006, p. 66). 
À vista disso, o signo se mostra como uma "[...] arena onde se desenvolve a luta de classes. [...] Na verdade, é este entrecruzamento dos índices de valor que torna o signo vivo e móvel, capaz de evoluir [...]" (BAKHTIN, 2006, p. 45-46). Desta forma, esperamos compreender como a internacionalização da educação e as consequentes transformaç̧ões de signo linguístico refletem na missão do ensino escolar brasileiro, haja vista a influência direta sobre a atuação das escolas, dos educadores e das comunidades escolares de uma forma geral, que passam, inevitavelmente, a voltar atenção para novos propósitos, novas formas de atuação, de avaliação etc., operando sob a força de novas palavras, novas realidades ideológicas, ainda que sem a exata consciência dessa dinâmica e de suas implicações.

Tomamos como referencial a perspectiva bakhtiniana de linguagem, pois entendemos que o diálogo e a interação com pesquisas encontradas na BDTD do Ibict e no Portal de Periódicos da Capes são caminhos possíveis, tendo em vista os objetivos e a possibilidade de reconhecer discursos, percepções e práticas que marcam nossa organização socioeducacional. Optamos desse modo, por uma pesquisa bibliográfica, de caráter exploratório e analítico, que permite compreender enunciações, levantar os acontecimentos e as repercussões, evidenciar a realidade ideológica sobre a qual as concepções e as práticas investigadas se fundamentam.

Buscaremos de tal modo, refletir sobre o histórico de reformas das políticas públicas de educação no Brasil, em diálogo com as influências de diretrizes provenientes de conferências e/ou de fóruns mundiais de educação, e com nosso referencial teórico, em busca do desvelamento de forças e de concepções que fundamentam e/ou perpassam enunciados, concepções e práticas educacionais, a fim de avaliar implicações para a missão do ensino escolar brasileiro.

\section{Políticas públicas educacionais no Brasil e a influência de organismos internacionais}

Antes de nos debruçarmos sobre o histórico de reformas educacionais brasileiras, entende-se que é interessante conceituar, mesmo que brevemente, política pública e neoliberalismo, para evidenciar a contradição que marca os conceitos em meio ao contexto em que são apresentados neste trabalho.

O campo de estudos sobre política pública compreende uma área de conhecimento que se encontra em constante discussão, e ainda que não haja consenso 
SCHWARTZ, C. M., BATISTA, P. V. Internacionalização das políticas educacionais brasileiras: desdobramentos sobre a missão do ensino escolar

sobre seu conceito, pode-se compreender como ações, decisões, medidas regulatórias e leis que os governos municipais, estaduais ou federal desenvolvem para atender a demandas que emergem da sociedade civil (SOUZA, 2006).

A cientista política Souza (2006), ao apresentar uma revisão de literatura sobre política pública, aponta para uma área que tem origem nos Estados Unidos da América, no final do século $\mathrm{XX}$, compreendendo uma modalidade de estudos dedicada às produções dos governos, contudo, nascido no âmbito acadêmico, sem qualquer vínculo com ações dos Estados, podendo ser pensada como:

[...] o campo do conhecimento que busca, ao mesmo tempo, "colocar o governo em ação" e/ou analisar essa ação (variável independente) e, quando necessário, propor mudanças no rumo ou curso dessas ações (variável dependente). A formulação de políticas públicas constitui-se no estágio em que os governos democráticos traduzem seus propósitos e plataformas eleitorais em programas e ações que produzirão resultados ou mudanças no mundo real (SOUZA, 2006, p. 26).

Indo de encontro a essa realidade, o neoliberalismo surge no século XX com a defesa de que o Estado não deve intervir na economia, da mesma forma que a economia não deve intervir no Estado, defendendo assim a concepção de Estado mínimo, dando ao mercado a capacidade de regulação do trabalho e do capital.

A partir dessa concepção neoliberal, as políticas públicas e as intervenções do Estado são compreendidas como responsáveis pelas crises enfrentadas pelas nações, uma vez que ferem o direito à liberdade e à individualidade, vistas como fundamentais em uma sociedade capitalista que exige adaptação e uma série de competências e habilidades para lidar com as demandas do capital.

Há aqui uma incongruência que esperamos evidenciar com o desenrolar do texto, mas chamamos atenção de antemão para o caráter localizado da política pública, marcada pelo vício de origem, em contraposição às diretrizes internacionais que o projeto neoliberal de educação levou a incidir sobre a realidade brasileira.

Analisando o histórico de reformas educacionais empreendidas no Brasil, apresentado por Hilário, Queiroz e Silva (2017), pecebe-se que, desde a instalação da Companhia de Jesus - que pode ser considerada a primeira organização pedagógica a compor o nosso sistema educacional, entre os anos 1549 e 1759 -, até fins dos anos 1980, quando se reestabelecia a democracia e discutia-se a Lei de Diretrizes e Base da Educação (LDB) - Lei no 9.394, promulgada somente em 1996 -, não houve influência 
significativa de diretrizes internacionais nas políticas públicas e/ou nas reformas educacionais implementadas.

Durante o referido período, destaca-se apenas um episódio em que, mediante a Reforma Capanema (1942), institui-se, dentre outros, o ensino industrial, comercial, agrícola, criou-se o Senai e o Senac, reforçando o dualismo entre a possibilidade de uma formação técnica (visando atuação no mercado de trabalho) e uma formação universitária (visando a formação humana do ser). Neste momento da história educacional brasileira, destacam-se os primeiros incentivos de organismos internacionais para as escolas técnicas, sem, contudo, refletir em grandes transformações naquela realidade (HILÁRIO; QUEIROZ; SILVA, 2017).

Florencio, Fialho e Almeida (2017), descrevem o contexto dos países chamados de terceiro mundo, subdesenvolvidos ou em desenvolvimento nos anos 1980, constituindo-se pela incidência de dívida externa, à qual, no Brasil, mantinha forte relação com as políticas neoliberais, que visam ações de liberalização e de desregulação dos mercados, em detrimento de menos participação e de menos responsabilidade do Estado na oferta de serviços públicos básicos. Tais realidades se mostraram favoráveis para atuação do Banco Mundial (BM) - organização criada em 1944, junto de outros órgãos, como: Fundo Monetário Internacional (FMI) e Banco Internacional para a Reconstrução e Desenvolvimento (Bird) -, com o intuito de reduzir desigualdades sociais, contribuir na reconstrução dos países após a Segunda Guerra Mundial.

Como consequência do processo de globalização, o BM passou a unir-se à inúmeras outras organizações, atuar internacionalmente na garantia de serviços básicos, disponibilizando empréstimos às nações em desenvolvimento, implementando infraestruturas, políticas sociais, econômicas e de controle, mediante a oferta de serviços básicos, como: saúde, saneamento e educação (MILAGRE, 2017; FLORENCIO; FIALHO; ALMEIDA, 2017).

Libâneo (2016) aponta, além do BM, a atuação de destaque, na área educacional, das instituições: Programa das Nações Unidas para o Desenvolvimento (Pnud), Organização das Nações Unidas para a Educação, Ciência e a Cultura (Unesco), Organização para a Cooperação e Desenvolvimento Econômico (OCDE) e o Banco Interamericano de Desenvolvimento (Bid). São algumas das organizações que atuam para a internacionalização da educação, ou seja, na reestruturação das instituições de ensino e todo seu funcionamento, para adequar-se aos padrões e às intenções das 
grandes potências mundiais, conforme as agendas planejadas globalmente para a educação, influenciando assim na elaboração de documentos, diretrizes, leis, projetos, programas etc., visando a integração das nações (MILAGRE, 2017).

No cenário brasileiro, observa-se que as políticas educacionais criadas a partir da década de 1990, mantêm relação direta com diretrizes internacionais provenientes de documentos gerados a partir de conferências e de fóruns mundiais de Educação. Vários são os estudos que já se dedicaram a analisar e a confirmar tais influências e impactos sobre as políticas públicas brasileiras ${ }^{7}$. Alguns eventos internacionais destacam-se como grandes influenciadores, conforme apresentado por Antunes, Zwetsch e Sarturi (2017), e adaptado a seguir:

- Conferência Mundial de Educação para Todos de Jomtien, realizada na Tailândia em 1990. Influenciou as seguintes políticas brasileiras:

- Plano Decenal de Educação para Todos de 1993.

- Lei no 9.394 (LDBEN) de 1996.

- Fórum Mundial de Educação para Todos de Dakar, realizado em 2000. Influenciou as seguintes políticas brasileiras:

- Lei no 10.172 (PNE)de 2001.

- Lei no 11.114 de 2005.

- Lei no 11.274 de 2006.

- EC nํ 59 de 2009.

- Lei no 12.796 de 2013.

- Lei no 13.005 (PNE)de 2014.

- Fórum Mundial de Educação para Todos de Incehon, realizado na Coreia do Sul em 2015. Influenciou a:

- Lei no 13.415 de 2017.

Não pretendemos detalhar exatamente como se deram as influências em cada política mencionada, são fatos discutidos em inúmeros trabalhos já mencionados. Daremos alguns exemplos a título de ilustração/contextualização e nos dedicaremos a pensar os desdobramentos sobre a missão do ensino escolar.

A Conferência de Jomtien (1990), representa um divisor de águas que marca a inauguração da ideologia neoliberal no Brasil. Foi realizada em conjunto com o BM, a Unesco, o Pnud e o Fundo das Nações Unidas para a Infância (Unicef), deu origem à

${ }^{7}$ Dentre eles estão: Libâneo (2012), Silva (2014) e Fernandes (2015). 
Declaração Mundial sobre Educação para Todos e foi destinada ao grupo intitulado E-9, na época os países com as maiores taxas de analfabetismo (composto por Bangladesh, Brasil, China, Egito, Índia, Indonésia, México, Nigéria e Paquistão), os quais comprometeram-se a desenvolver políticas públicas destinadas a oferecer educação para todos, incluindo mulheres, adultos e deficientes, visando combater o analfabetismo e a pobreza (FLORENCIO; FIALHO; ALMEIDA, 2017).

Desde então, toda uma agenda educacional com financiamentos, revisões de currículos, formação de sistemas de avaliação e de controle, passou a ser implementada. No Brasil observou-se reflexo desse acordo na aprovação da Emenda Constitucional no 14, de setembro de 1996 - que reorganizou o financiamento educacional, concentrando recursos no ensino fundamental; na aprovação da LDB, Lei no 9.394/1996 estabelecendo alterações em todo sistema de ensino, desde a educação básica até o ensino superior, inclusive na formação de professores; e na instituição do Fundo de Manutenção e Desenvolvimento do Ensino Fundamental e Valorização do Magistério (Fundef), pela Lei no 9.424 de 1996 - a partir do qual o financiamento foi voltado prioritariamente para o ensino fundamental. De acordo com Florencio, Fialho e Almeida (2017), tais mudanças repercutiram em políticas públicas de:

[...] descentralização da gestão e gerência dos recursos financeiros; mudanças curriculares com a publicação dos Parâmetros Curriculares Nacionais (PCN); fortalecimento do sistema de avaliação de desempenho dos alunos através do Sistema de Avaliação da Educação Básica (Saeb), bem como da criação de muitos outros que emergem com o objetivo de avaliar alunos de todos os níveis de ensino; além da preocupação com a formação docente, que a LDB n. 9.394/1996 traz com a expressão "formação de profissionais da Educação" (FLORENCIO; FIALHO; ALMEIDA, 2017, p. 306).

Em síntese, fortaleceu-se a necessidade de uma série de medidas para assegurar entrada, permanência e sucesso escolar, entre elas o investimento na formação e na atuação dos professores, difundindo-se assim o projeto educacional nos moldes neoliberais.

Visando a universalização da educação básica, foi realizado, em 2000, o Fórum Mundial de Educação para Todos, em Dakar, momento em que os países membros da Unesco, somados a organizações, agências, grupos e associações, avaliaram progressos desde Jomtien (1990) e ampliaram as metas, priorizando valorização e qualificação dos professores, repercutindo assim em outras reformulações e em políticas públicas 
SCHWARTZ, C. M., BATISTA, P. V. Internacionalização das políticas educacionais brasileiras: desdobramentos sobre a missão do ensino escolar

educacionais nas nações participantes, conforme apresentam Milagre (2017), Antunes, Zwetsch e Sarturi (2017).

0 documento resultante do fórum aponta como ação central: atender necessidades básicas de aprendizagem, tanto de crianças, jovens e adultos, universalizando o acesso à escola e erradicando o analfabetismo. Define ainda os quatro pilares: aprender a aprender, aprender a fazer, aprender a conviver e aprender a ser (MILAGRE, 2017).

Em 2015, na Coreia do Sul, apoiados ainda nas definições de Jomtien (1990) e de Dakar (2000), ocorreu o Fórum Mundial de Educação para Todos, em Incheon, reforçando compromissos e metas a serem alcançadas até 2030. Nesta versão, tornou-se prioridade o investimento na formação e atuação docente, tendo em vista a oferta de educação de qualidade, igualitária e inclusiva de aprendizagem ao longo da vida para todos. Tais concepções fundamentam as metas de educação dos Objetivos de Desenvolvimento Sustentável (ODS) da Agenda 2030, da Organização das Nações Unidas (ONU), conforme afirmam Antunes, Zwetsch e Sarturi (2017).

Vê-se que emergem do cenário brasileiro da década de 1990 avanços neoliberais e expressões do mundo globalizado, mediante influência do capital financeiro internacional, sobretudo nas políticas educacionais que passam a ser influenciadas por organismos multilaterais de desenvolvimento. Tais relações tendem a resultar em:

[...] perda da identidade do sistema educacional brasileiro, ou de quaisquer outros países, em virtude do enquadramento dos modelos educacionais locais às agendas externas, que em sua maioria não respeitam as realidades locais por desconhecerem os aspectos históricosociais que geraram a construção da identidade cultural local, visto que visam apenas a manutenção de seu status quo, ou seja, de opressores e lideres hegemônicos numa visão Gramnisciana. Nisto, é preocupante que os sistemas de ensino sejam forçados a se remodelarem a tal perspectiva formando mão-de-obra, barata e supostamente qualificada, para o capital, que em tese afirma que isso levaria ao alívio da pobreza e ao crescimento social (HILÁRIO; QUEIROZ; SILVA, 2017, p. 183, itálico dos autores).

Observa-se assim, que com o discurso de incentivar o crescimento econômico, aliviar a pobreza, combater o analfabetismo e democratizar o acesso à educação (mazelas que marcam a realidade brasileira até a atualidade), os organismos internacionais lançam estratégias ligadas à economia, transformando a educação em uma espécie de mercadoria, transferindo tais serviços para o setor privado, impedindo 
SCHWARTZ, C. M., BATISTA, P. V. Internacionalização das políticas educacionais brasileiras: desdobramentos sobre a missão do ensino escolar

que sejam tratados em âmbito público e local, como prioridade de uma nação, indo de encontro ao conceito de política pública apresentado no início deste capítulo.

\section{Desdobramentos sobre a missão do ensino escolar}

Cientes de que a compreensão sobre as finalidades da educação, os indicadores de qualidade, assim como a missão do ensino escolar são fundamentais e reverberam na elaboração de políticas, programas, currículos, conteúdos e práticas, buscaremos neste capítulo identificar as concepções de educação que rondam o universo educacional, analisar em especial a concepção proveniente das diretrizes internacionais e seus desdobramentos na realidade do ensino brasileiro.

Baseamo-nos em Bakhtin (2006) para evidenciar que “[...] Tudo que é ideológico possui um significado e remete a algo situado fora de si mesmo. Em outros termos, tudo que é ideológico é um signo [...]" (BAKHTIN, 2006, p. 29, itálico do autor).

[...] Um signo não existe apenas como parte de uma realidade; ele também reflete e refrata uma outra. Ele pode distorcer essa realidade, ser-lhe fiel, ou apreendê-la de um ponto de vista específico, etc. Todo signo está sujeito aos critérios de avaliação ideológica (isto é, se é verdadeiro, falso, correto, justificado, bom, etc.). 0 domínio do ideológico coincide com o domínio dos signos: são mutuamente correspondentes. Ali onde o signo se encontra, encontra-se também o ideológico. Tudo que é ideológico possui um valor semiótico (BAKHTIN, 2006, p. 30, itálico do autor).

Desta forma, o enunciado aqui sistematizado, fundamentado nos estudos, nas concepções e nas percepções alcançadas no decorrer da pesquisa, nos coloca também em posição de estabelecer diálogo com o problema investigado, e ao fazê-lo não haverá possibilidade de neutralidade, nos posicionaremos conforme as nossas concepções de sujeitos histórico-sociais e segundo nossas próprias visões de mundo.

"Realizando-se no processo da relação social, todo signo ideológico, e portanto também o signo lingüístico, vê-se marcado pelo horizonte social de uma época e de um grupo social determinados [...]" (BAKHTIN, 2006, p. 43, itálico do autor). Assim, retomando o contexto dos anos 1990, haviam, basicamente, duas concepções sobre educação, uma que pressupunha oportunidades sociais, mediante ascensão da 
SCHWARTZ, C. M., BATISTA, P. V. Internacionalização das políticas educacionais brasileiras: desdobramentos sobre a missão do ensino escolar

democracia, e outra que apontava para o individualismo e para o enriquecimento pessoal nos moldes neoliberais que insurgiam na época (MILAGRE, 2017).

Atualmente, em meio às divergências sobre o que seja uma escola, pode-se identificar, pelo menos, três orientações curriculares ou formas de uma instituição de ensino funcionar, apontadas por Libâneo (2016) ao discutir visões de ensino e de escola, são elas:

- segundo o que pressupõe os organismos internacionais - que veem a escola como caminho para implementar programas de combate à pobreza e à exclusão social, apostando em currículos instrumentais ou de resultados imediatos, a partir dos quais destacam-se o ensino técnico e profissional;

- com base em orientações sociológicas e/ou interculturais - dedicadas a experiências educativas socioculturais, baseando-se na troca de valores, solidariedade, diversidade cultural e social;

- segundo orientação dialética-crítica - que se apoia na teoria histórico-cultural ou em pedagogias sociocríticas, defendendo o currículo dedicado à formação cultural e científica em meio às práticas socioculturais. Neste modelo a escola destaca-se como propagadora da democracia, da inclusão social, sendo responsável por oferecer meios de aprendizagem de conhecimentos e de desenvolvimento intelectual a partir de processos de ensino-aprendizagem.

A primeira concepção refere-se à perspectiva neoliberal, inserida no Brasil na década de 1990, conforme contextualizado no capítulo anterior. Os indícios do percurso da pesquisa apontam ser essa a concepção hegemônica, mesmo nos dias atuais, a qual privilegiamos neste estudo.

Trata-se de um modelo de educação, segundo o qual a escola é compreendida como um instrumento para solucionar problemas econômicos e sociais, assumindo funções que, por vezes, nem são propriamente da escola, por meio da defesa de causas como o alívio da pobreza e/ou de conflitos sociais, tendo em vista o acolhimento social, o desenvolvimento humano, a inclusão, enfim, apontando, à primeira vista, para realidades inquestionáveis, urgentes e fundamentais à dignidade humana. Entretando, Bakhtin (2006) destaca que,

[...] aquilo mesmo que torna o signo ideológico vivo e dinâmico faz dele um instrumento de refração e de deformação do ser. A classe dominante tende a conferir ao signo ideológico um caráter intangível e acima das diferenças de classe, a fim de abafar ou de ocultar a luta dos índices 
SCHWARTZ, C. M., BATISTA, P. V. Internacionalização das políticas educacionais brasileiras: desdobramentos sobre a missão do ensino escolar

sociais de valor que aí se trava, a fim de tornar o signo monovalente (BAKHTIN, 2006, p. 46).

Ocorre que esta perspectiva leva a uma subordinação da escola ao mercado de trabalho, que passa a ser uma difusora da ideologia neoliberal, visto que a real intencionalidade é preparar o indivíduo para desenvolver sua força produtiva e assim ter condições mínimas de contribuir no desenvolvimento socioeconômico.

Com a diminuição da participação do Estado, transfere-se para o mercado a responsabilidade de atuar na educação, a escola vai sendo transformada em uma espécie de empresa, que presta serviços para os alunos, que, como clientes, esperam qualidade mediante a compra do produto, que, por sua vez, é a educação para o trabalho.

Trata-se de uma configuração que compromete seriamente a missão da escola, o entendimento sobre qual seja a sua verdadeira finalidade, quais os conhecimentos e a formação que deve proporcionar aos alunos, quais critérios que apontam para qualidade do ensino, que tipo de currículo deve ser implementado, enfim, perde-se, facilmente, o rumo e a compreensão da verdadeira missão da educação escolar. Vê-se assim, que

$\mathrm{Na}$ realidade, todo signo ideológico vivo tem, como Jano, duas faces. Toda crítica viva pode tornar-se elogio, toda verdade viva não pode deixar de parecer para alguns a maior das mentiras. Esta dialética interna do signo não se revela inteiramente a não ser nas épocas de crise social e de comoção revolucionária. Nas condições habituais da vida social, esta contradição oculta em todo signo ideológico não se mostra à descoberta porque, na ideologia dominante estabelecida, o signo ideológico é sempre um pouco reacionário e tenta, por assim dizer, estabilizar o estágio anterior da corrente dialética da evolução social e valorizar a verdade de ontem como sendo válida hoje em dia. Donde o caráter refratário e deformador do signo ideológico nos limites da ideologia dominante (BAKHTIN, 2006, p. 46, itálico do autor).

Milagre (2017), em dissertação de mestrado, apresenta uma comparação entre finalidades e critérios de qualidade da educação, apontados por organismos internacionais, como o BM e a Unesco, em contraposição ao que se afirma em documentos do Ministério da Educação no Brasil.

O cotejamento aponta que há significativa semelhança entre os documentos, pois entendem que “[...] a educação básica deve estar centrada na aquisição e nos resultados efetivos da aprendizagem, no desenvolvimento do educando, seu preparo para o exercício da cidadania e sua qualificação para o trabalho [...]" (MILAGRE, 2017, p. 98). 
SCHWARTZ, C. M., BATISTA, P. V. Internacionalização das políticas educacionais brasileiras: desdobramentos sobre a missão do ensino escolar

Em todos os casos a educação é apontada como acolhimento social, solução para problemas socioeconômicos, em consonância com demandas que emergem do contexto global, e assim os sistemas de avaliação tornam-se muito importantes:

A política de avaliação é ressaltada nos documentos, ela é considerada um artifício capaz de fomentar a qualidade no ensino, pois, possibilita o controle público dos resultados. Voltado para um enfoque econômicosocial e para o meio empresarial, a qualidade da educação significa preparar o indivíduo para adequar-se ao mercado de trabalho, para a competitividade e produtividade, o que nos leva a associar a escola com o sistema produtivo (MILAGRE, 2017, p. 97-98).

O alcance da qualidade depende então da oferta de conteúdos elementares, pensados nos currículos instrumentais ou de resultados imediatos, descrito por Libâneo (2016) como:

[...] um conjunto de conteúdos mínimos necessários ao trabalho e emprego, associado ao currículo de convívio e acolhimento social, com forte apelo à inclusão social e ao atendimento da diversidade social, visando a formar para um tipo de cidadania baseado na solidariedade e na contenção de conflitos sociais. Ambos são adotados, presentemente, na maioria dos estados brasileiros. Esse currículo de resultados caracteriza-se pela formulação de metas de competências, repasse de conteúdos apostilados, mecanização das aprendizagens, treinamento para responder testes, passando ao largo das características psicológicas, sociais e culturais dos alunos, das práticas socioculturais vividas em seu entorno social, bem como do contexto histórico e dos níveis de decisão do currículo, tal como mostram recentes estudos de Simônia Silva (2014) e Fernandes (2015). Não se trata, portanto, de uma escola voltada para ensinar conhecimentos significativos, contribuir para a promoção e a ampliação dos processos psíquicos superiores, ajudar a compreender e analisar a realidade e desenvolver processos de pensamento. Ao contrário, é uma escola centrada em conhecimentos práticos, em habilidades e maneiras de fazer, visando a empregabilidade precária para os que vivem somente do trabalho (LIBÂNEO, 2016, p. 49).

Dentro dessa lógica, o ensino de conteúdos científicos, o desenvolvimento intelectual e cognitivo, a formação humana e cultural, a dinâmica e o alcance dos processos de ensino-aprendizagem, a importância do professor, da didática e da pedagogia são todos comprometidos, colocados em último lugar de importância para atender a padrões, avaliações, modelos e métodos impostos pela internacionalização, ou seja, a educação não se presta a atuar sobre a (trans)formação das realidades e dos indivíduos que compõe a comunidade escolar, sua atuação reduz-se a oferecer conteúdos mínimos, comprometidos com a preparação básica das forças de trabalho 
para a rápida empregabilidade, em detrimento da formação integral, omnilateral, necessária à emancipação humana e social dos indivíduos.

\section{Considerações finais}

O presente estudo buscou compreender como diretrizes provenientes de conferências e/ou de fóruns mundiais de educação vêm, historicamente, repercutindo na elaboração de importantes reformas educacionais e na missão do ensino escolar brasileiro.

Destacou-se entre os principais marcos, a partir dos quais percebeu-se influências de diretrizes internacionais nas políticas públicas educacionais do Brasil: a Conferencia Mundial de Educação para Todos de Jomtien (1990), o Fórum Mundial de Educação para Todos de Dakar (2000) e o Fórum Mundial de Educação para Todos de Incehon (2015), repercutindo em uma série de medidas para assegurar entrada, permanência e sucesso escolar, difundindo o projeto educacional nos moldes neoliberais.

Identificou-se as instituições internacionais que se destacam no processo de internacionalização da educação, dentre elas: BM, Pnud, Unesco, OCDE e Bid. Instituições que atuam internacionalmente para a redução das desigualdades sociais; disponibilizando empréstimos às nações em desenvolvimento; implementando infraestrutura, políticas sociais, econômicas e de controle, mediante a oferta de serviços básicos (como saúde, saneamento e educação, por exemplo); e mediante implementação de programas e de planos de ação comprometidos com exigências e metas a serem alcançadas pelas nações.

Compreendeu-se como a internacionalização da educação reverbera desastrosamente na missão do ensino escolar brasileiro. Não tivemos a pretensão de julgar pontos positivos e/ou negativos do projeto neoliberal (este não era exatamente o objetivo deste estudo), mas o que se destacou como lamentável é a educação estar sendo explorada, desde a década de 1990, como via para sua implementação, pela gerência de 
SCHWARTZ, C. M., BATISTA, P. V. Internacionalização das políticas educacionais brasileiras: desdobramentos sobre a missão do ensino escolar

organismos internacionais, que não estão, exatamente, comprometidos com os verdadeiros desafios da educação brasileira.

A escola não deve ser nunca indiferente às vulnerabilidades sociais que marcam as realidades brasileiras, contudo, não pode ter sua essência pedagógica (a missão de ensinar conteúdos, desenvolver cognitiva e intelectualmente os alunos e o comprometimento com uma formação humana e cultural ampla), colocada de lado para atuar em causas de alívio social. A educação é inclusive uma dessas causas fundamentais à vida humana, e está sendo comprometida em detrimento das demais, enfraquecendo assim a contribuição que efetivamente daria para a diminuição das desigualdades e para as transformações sociais necessárias aos contextos locais e nacional.

À vista disso, vê-se que tem sido retirado das políticas públicas e das escolas o seu potencial transformativo, comprometendo avanços sobre a qualidade dos processos de ensino-aprendizagem, reverberando no baixo desempenho dos alunos, constatado pelos próprios índices de reprovação do referido sistema, levando ao fracasso escolar e à exclusão social.

\section{Referências}

ANTUNES, Jucemara; ZWETSCH, Patrícia dos Santos; SARTURI, Rosane Carneiro. As Influências das Orientações de Organismos Internacionais nas Políticas Públicas Educacionais para a Educação Básica no Brasil. In: CONGRESSO NACIONAL DE EDUCAÇÃO, 13., 2017, Curitiba. Comunicação [...]. Curitiba: Educere, 2017. Disponível em: http://educere.bruc.com.br/arquivo/pdf2017/26198 14006.pdf. Acesso em: 7 maio 2019.

BAKHTIN, Mikhail Mikhailovich. Marxismo e filosofia da linguagem. 12. ed. [São Paulo]: Hucitec Editora, 2006. Disponível em: https://hugoribeiro.com.br/bibliotecadigital/Bakhtin-Marxismo filosofia linguagem.pdf. Acesso em: 5 maio 2019.

EVANGELISTA, Olinda; SHIROMA, Eneida Oto. Educação para o alívio da pobreza: novo tópico da agenda global. Revista de Educação PUC-Campinas, Campinas, n. 20, p. 4354, jun. 2006. Disponível em: http://periodicos.puccampinas.edu.br/seer/index.php/reveducacao/article/view/220. Acesso em: 5 maio 2019.

FERNANDES, Silvia Reis. Concepções e práticas de avaliação vigentes em escolas públicas: a influência das políticas educacionais no trabalho dos professores. 2015. Dissertação (Mestrado em Educação) - Pontifícia Universidade Católica de Goiás, Goiânia, 2015. Disponível em: http://tede2.pucgoias.edu.br:8080/handle/tede/1132. Acesso em: 9 maio 2019. 
FLORENCIO, Lourdes Rafaella Santos; FIALHO, Lia Machado Fiuza; ALMEIDA, Nadja Rinelle Oliveira de. Política de Formação de Professores: a ingerência dos Organismos Internacionais no Brasil a partir da década de 1990. HOLOS, ano 33, v. 5, p. 303-312, 2017. Disponível em:

http://www2.ifrn.edu.br/ojs/index.php/HOLOS/article/view/5757. Acesso em: 5 maio 2019.

FRIGOTTO, Gaudêncio; CIAVATTA, Maria. Educação básica no Brasil na década de 1990: subordinação ativa e consentida à lógica de mercado. Educação e Sociedade, Campinas, v. 24, n. 82, p. 93-130, abr. 2003. Disponível em:

https://www.scielo.br/scielo.php?pid=S0101-73302003000100005\&script=sci arttext. Acesso em: 7 maio 2019.

HILÁRIO, Thiago Wedson; QUEIROZ, Vanderlei da Rosa de Freitas; SILVA, Helaíny Waniessy Kenia Rodrigues. A que(m) se destinam as Reformas Educacionais a partir da década de 1990? In: SEMANA DE LICENCIATURA, 14.; SEMINÁRIO DA PÓS-GRADUAÇÃO EM EDUCAÇÃO PARA CIÊNCIAS E MATEMÁTICA, 5., 2017, Goiás. Anais [...]. Goiás: Instituto Federal Goiás, câmpus Jataí, 2017, p. 179-188. Disponível em: http://w2.ifg.edu.br/jatai/semlic/seer/index.php/anais/article/viewArticle/563. Acesso em: 7 maio 2019.

LIBÂNEO, José Carlos. 0 dualismo perverso da escola pública brasileira: escola do conhecimento para os ricos, escola do acolhimento social para os pobres. Educação e Pesquisa, São Paulo, v. 38, n. 1, p. 13-28, jan./mar. 2012. Disponível em: https://www.scielo.br/scielo.php?pid=S151797022011005000001\&script=sci arttext\&tlng=pt. Acesso em: 5 maio 2019.

LIBÂNEO, José Carlos. Políticas educacionais no Brasil: desfiguramento da escola e do conhecimento escolar. Cadernos de Pesquisa, São Paulo, v. 46, n. 159, p. 38-62, jan./mar. 2016. Disponível em: https://dialnet.unirioja.es/servlet/articulo?codigo=5624294. Acesso em: 7 maio 2019.

MILAGRE, Gessica Filgueiras. Finalidades Educativas Escolares na Política Educacional Brasileira e Organismos Internacionais: a questão da qualidade de ensino. 2017. Dissertação (Mestrado em Educação) - Pontifícia Universidade Católica de Goiás, Goiânia, 2017. Disponível em:

http://tede2.pucgoias.edu.br:8080/handle/tede/3840. Acesso em: 5 maio 2019.

SILVA, Simônia Peres da. 0 processo de implementação das políticas educacionais e repercussões nas formas de gestão da escola e no processo de ensinoaprendizagem: o Pacto pela Educação em Goiás. 2014. Tese (Doutorado em Educação) - Pontifícia Universidade Católica de Goiás, Goiânia, 2014. Disponível em: http://tede2.pucgoias.edu.br:8080/handle/tede/709. Acesso em: 9 maio 2019.

SOUZA, Celina. Políticas públicas: uma revisão da literatura. Sociologias, Porto Alegre, ano 8, n. 16, p. 20-45, jul./dez. 2006. Disponível em: http://www.scielo.br/pdf/soc/n16/a03n16. Acesso em: 7 maio 2019. 
SCHWARTZ, C. M., BATISTA, P. V. Internacionalização das políticas educacionais brasileiras: desdobramentos sobre a missão do ensino escolar

Recebido emDezembro de 2020

Aprovado em Janeiro de 2020

Publicado em Fevereiro de 2021 


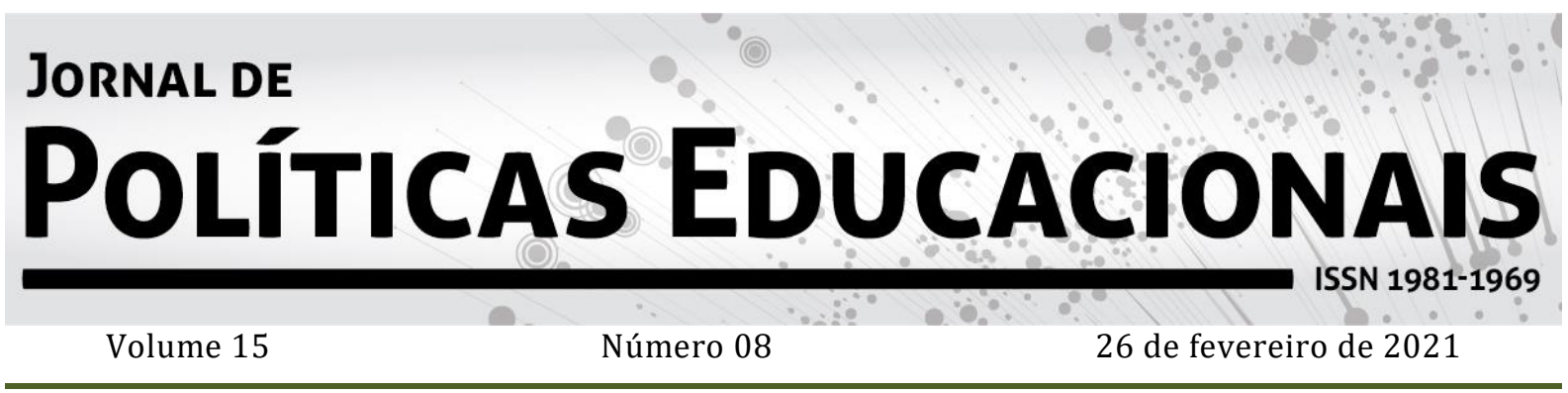

\begin{abstract}
(c)
SOREERIGHISRESERNED O Copyright é retido pelo/a autor/a (ou primeiro co-autor) que outorga o direito da primeira publicação ao Jornal de Políticas Educacionais. Mais informação da licença de CreativeCommons encontram-se em http://creativecommons.org/licenses/by-nc-nd/2.5.Qualquer outro uso deve ser aprovado em conjunto pelo/s autor/es e pelo periódico.

Jornal De Políticas EduCACionais é uma publicação do Núcleo de PolíticasEducacionaisdo Setor de Educação da Universidade Federal do Paraná - NuPE/UFPR, em consórcio com a Linha de Pesquisa em Políticas Educacionais do Programa de Pós-Graduação em Educação - PPGE/UFPR, que aceita colaboração, reservando-se o direito de publicar ou não o material espontaneamente enviado à redação. As colaborações devem ser enviadas ao NuPE/UFPR, conforme orientações contidas nas páginas do periódico na internet: http://revistas.ufpr.br/jpe.
\end{abstract}

INDEXAÇÃO:

BASE DE DADOS
Sumário.Org
Google Scholar
BASE
Dimensions

DIRETÓRIOS
Erih Plus
Latindex
Diadorim
EZB
ROAD
Journal 4-free

\author{
ÍNDICES \\ Index Copernicus \\ Cite Factor \\ PORTAIS \\ LiVre \\ Capes \\ Science Open \\ World Wide Science
}

(Periódico integralmente disponível apenas em via eletrônica)

Jornal de Políticas Educacionais / Núcleo de Políticas Educacionais da Universidade Federal do Paraná NuPE/UFPR - v.1, n. 1 (1을 semestre de 2007) - Curitiba: NuPE/UFPR.

Volume 15, número 08 - Fevereiro de 2021

ISSN 1981-1969

1. Educação - Periódicos. 2. Política Educacional - Periódicos. I. NuPE/UFPR 
Comitê Editorial:

Elisângela Scaff (UFPR)

Daniela de Oliveira Pires (UFPR)

Conselho Editorial:

Andréa Barbosa Gouveia (UFPR - Brasil), Angela Maria Martins (FCC, Brasil), Antonia Almeida Silva (UEFS, Brasil), Cesar Tello (Universidad Nacional Tres Febrero, Argentina), Cristiane Machado (Unicamp- Brasil), Elton Luiz Nardi (UNOESC, Brasil), Fernanda Saforcada (Universidad de Buenos Aires - UBA - Argentina), Gladys Beatriz Barreyro (USP - Brasil), Gilda Cardoso Araújo (UFES - Brasil), Gustavo Enrique Fischman (Arizona State University - USA), Janete Maria Lins de Azevedo (UFPE, Brasil), Jefferson Mainardes (UEPG - Brasil), João Ferreira de Oliveira (UFG - Brasil), Jorge Manuel Gorostiaga (UNSAM - Argentina), Juca Gil (UFRGS - Brasil), Luciana Rosa Marques (UFPE, Brasil), Luiz Souza Júnior (UFPB - Brasil), Marcia Aparecida Jacomini (Unifesp-Brasil), Maria Dilnéia Espíndola Fernandes (UFMS, Brasil), Ney Cristina Monteiro de Oliveira (UFPA - Brasil), Nicolás Bentancur, (Universidad de la República de Uruguay), Nora Krawczyk (Unicamp- Brasil) Rodrigo da Silva Pereira (UFBA, Brasil), Robert Verhine (UFBA - Brasil), Rosana Cruz (UFPI - Brasil), Rubens Barbosa Camargo (USP - Brasil), Sebastián Donoso Díaz (Universidad de Talca - Chile), TheresaAdrião (UNICAMP - Brasil), Vera Maria Vidal Peroni (UFRGS - Brasil).

Créditos e Agradecimentos:

Revisão de Língua Portuguesa, Abstract e Resumen: Programa de apoio às publicações científicas periódicas da UFPR

Arte e diagramação: Tiago Tavares (tiagotav@gmail.com)

Jornal de Políticas Educacionais

Universidade Federal do Paraná

Setor de Educação

Núcleo de Políticas Educacionais - NuPE/UFPR

Avenida Sete de Setembro, 2645

2 o andar, Sala 213

80.230-010 - Curitiba - PR - Brasil

Tel.: 41-3535-6264

jpe@ufpr.br

http://revistas.ufpr.br/jpe 